IFN Working Paper No. 713, 2007

\title{
Bargaining over a New Welfare State
} - A Model of the Regional Distribution of New Deal Funds Alessandro Bonatti and Kaj Thomsson 


\title{
Bargaining over a New Welfare State*
}

\author{
A Model of the Regional Distribution of New Deal Funds
}

\author{
Alessandro Bonatti ${ }^{\dagger}$ \\ Yale University
}

\author{
Kaj Thomsson $\ddagger$ \\ Yale University and RIIE
}

August 8, 2007

\begin{abstract}
The goal of this paper is twofold: First, to develop an estimable model of legislative politics in the US Congress. Second, to provide a greater understanding of the objectives behind the New Deal. In the theoretical model, the distribution of federal funds across regions of the country is the outcome of a bargaining game in which the President acts as the agenda-setter and Congress bargains over the final shape of the spending bill. For any given preferences (of the President) and distribution of seats in Congress, the model delivers a unique predicted allocation. Combined with data on New Deal programs, this is used to estimate the objectives of the Roosevelt administration. The results indicate that economic concerns for relief and recovery, though not necessarily for fundamental reform and development, largely drove New Deal spending. Political concerns also mattered, but more on the margin.
\end{abstract}

Keywords: C78, D72, H11, H50, N42, P48.

JEL Codes: Political Economy, Legislative Bargaining, New Deal, US Congress, Public Spending.

*We would like to thank Daron Acemoğlu, Hanming Fang, Tim Guinnane, David Mayhew, Ben Polak, Frances Rosenbluth, Kenneth Scheve, John Wallis and Gavin Wright for very helpful comments and discussions, as well as seminar audiences at Yale, the 2007 Midwest Political Science Association Conference and the Research Institute of Industrial Economics, Sweden. We also thank Florian Plöckl for his generous help with the regional characterizations and Price Fishback for kindly sharing his data with us.

†Yale University, Department of Economics, 28 Hillhouse Ave, New Haven CT 06520. E-mail: alessandro.bonatti@yale.edu.

${ }^{\ddagger}$ Yale University, Department of Economics, 37 Hillhouse Ave, New Haven CT 06520. Research Institute of Industrial Economics, Box 55665, 10215 Stockholm, Sweden. E-mail: kaj.thomsson@yale.edu. 


\section{Introduction}

The motivation behind the actions of politicians, a topic of intrinsic interest for political scientists, has received significant recent attention by quantitative political economists. For instance, key questions in the political agency literature center around the issue of whether, and if so how, the political process selects political decision-makers with the right intentions (and skills). ${ }^{1}$ More broadly, the entire formal political economy literature is in some sense built on the idea that governments cannot be treated as simple welfare-maximizers. Instead, in order to understand economic and public policy outcomes, the motivation and intentions of political decision-makers have to be carefully analyzed.

In the US, discussions about "what motivates government" naturally center around the period and programs described as the New Deal. This period was, by most accounts, the birth of the US welfare state. It was an era of unprecedented growth in total government spending, as well as in the scope of activities performed by the federal government. In the mid 1920's, just before the Great Depression and the New Deal, total federal (non-military) spending was approximately equal to 3 percent of GNP, while in the mid 1930's this figure had increased to about 10 percent. The support for state and local government expenditures from the federal level also increased dramatically. Earlier in the 20th Century, less than one percent of state and local revenues came from the federal government, while in the late 1930's about 15 percent of state and local revenues were due to federal aid. In addition, it created many of the government programs and structures, such as Social Security and various agricultural programs, that form the basis of the public sector in the US still to this day. $^{2}$

The New Deal was controversial already from the beginning and has stayed controversial ever since. The attacks have come from the left as well as from the right, on a number of different topics and from a number of different angles. Among many other critical accounts, the New Deal has been criticized by Zinn (1966) and Bernstein (1968) for being too conservative, by Powell (2003) and Cole and Ohanian (2004) for prolonging the Great Depression, by Libecap (1998) for instigating a lasting system of state intervention in agricultural markets, and by Flynn (1934) for being essentially a fascist undertaking.

Of particular relevance here is the official line of "the three R's" (relief, recovery and reform) emphasized by the New Dealers as the motivation behind this increase in federal spending and federal aid to the local level. However, Roosevelt's critics accused him of using national funds in order to reward Democratic states as well as to gain popularity in potential

\footnotetext{
${ }^{1}$ See, for instance, the work of Besley $(2004,2006)$ or Callander (2005).

${ }^{2}$ These values are taken from Wallis (1985) and Wallis (1998).
} 
swing states. Economic historians and public choice scholars have long been interested in this debate about the motivation behind the New Deal, and the determinants of the New Deal spending allocation. As stated by John Wallis, the question of focus in this literature has been:

Did Roosevelt and the New Dealers allocate money between states to achieve their stated goals of relief and reform by giving money to states with lower employment and lower incomes, or did they promote their own interests and allocate more money to states that were politically sensitive? [Wallis, 1998]

The empirical literature on this topic started with Reading (1973), who developed a simple model in order to test whether the New Deal spending pattern was in fact consistent with a focus on reform and relief/recovery. The second now-classic empirical study of the motivations behind the New Deal spending, Wright (1974), built on the analysis of Reading to investigate a potentially political motive behind the New Deal. These two studies generated a significant amount of following research. Recently, Anderson and Tollison (1991) included a number of variables intended to capture the role of Congress in the determination of the New Deal allocation.

These studies suggest that the regional distribution of the major New Deal programs might have been politically rather than economically motivated. However, in a series of papers, John Wallis $(1984,1985,1998)$ derives results that depart somewhat (though not completely) from this view. Wallis takes the position that political concerns did matter, but that the distribution of New Deal funds was primarily motivated by economic concerns. However, Wallis also shows that the economic reasons behind the programs interacted with political motives, making the different possible objectives hard to disentangle. ${ }^{3}$

To summarize, previous studies provide support for the idea that political purposes probably influenced the spending pattern of the New Deal. There is, however, no consensus on the question of how important the political calculations were, in relation to other possible objectives. A serious challenge is the interaction between economic and political concerns. Possibly, a formal treatment of this topic can provide additional structure helpful for the interpretation of the differing and sometimes non-comparable previous research. ${ }^{4}$

\footnotetext{
${ }^{3}$ This view is reinforced by the recent joint work of Price Fishback, Shawn Kantor and Wallis (2003).

${ }^{4}$ There are a few papers, such as Fleck $(1999,2001)$ and Strömberg (2004), that do develop formal models in order to interpret various aspects of the New Deal spending. These papers, however, differ significantly from ours in their methodological approach and/or their posed question. Fleck assumes that the President was trying to maximize his reelection probability. His findings broadly support they idea that political (reelection) concerns did matter, though he is not able to assess the relative importance of this and other motives. Strömberg, on the other hand, does estimate the structural parameters of his model. The model, however, is confined to an analysis of the impact of media on the spending of one particular program (FERA) - i.e. he does not attempt to say anything about the aggregate distribution of New Deal funds.
} 
Specifically, in this paper we develop a formal model of legislative politics in the US, applicable to the interaction between the President and the Congress during the implementation of new spending programs. The resulting allocation of funds is modeled as a function of the President's preferences and the distribution of seats in Congress, and the relevant parameters of the model are estimated using data from New Deal programs. The model takes into account the key features of the President-Congress bargaining game. However, it does not capture the full richness of the previous work on the New Deal, as the computational limitations implied by the formal modeling approach make this impossible. Hence, this paper should appropriately be viewed as a complement, not a substitute, to the existing research on the determinants of the allocation of New Deal funds.

In addition to the contribution it hopefully makes to the New Deal debate, this paper can be viewed as an attempt to place formal models of legislative politics in a more concrete setting. The bulk of theoretical (formal) political economy research on legislative politics is quite abstract and lacks institutional detail. Clearly, this previous research has generated very valuable general insights, e.g. on the role of constitutions and agenda-setting power for legislative outcomes, However, it provides limited guidance for understanding the outcome of particular legislative sessions or specific periods of major reform. Instead of a general theory of legislative bargaining, this paper provides a model of a specific legislative setting. ${ }^{5}$ That is, we adopt an alternative "case-based" or "bottom-up" approach to the formal modeling of legislatures. Hopefully, this approach can generate insights that would not trivially follow from more abstract models.

In the rest of the paper, we first describe extensively the formal political model, then derive a number of theoretical results characterizing legislative decision-making in the US Congress, and the outcome of the interaction between the President and Congress. All of this is done in Section 2. In Section 3 we discuss our regional classification of the US in the 1930s. In Section 4, we describe the data, and in Section 5 we provide an overview of the empirical approach as well as the estimation results. Finally, Section 6 contains a conclusion as well as a discussion of potentially interesting extensions.

\footnotetext{
${ }^{5}$ In this regard, our paper is perhaps most closely related to the work of Knight (2004, 2005), who estimates key parameters of the formal legislative bargaining model of Baron and Ferejohn (1989) in applied settings.
} 


\section{The Political Model}

\subsection{Overview}

\subsubsection{What's a good model of legislatures?}

It is far from obvious how a good model of legislative politics, applied to this particular context, should look like. At least three existing frameworks come to mind as related and potentially able to speak on the questions posed here. The first of these is the legislative bargaining literature, starting with the seminal contribution of Baron and Ferejohn (1989), which extends the theory of bargaining developed by Rubinstein (1982) to a political/legislative setting. ${ }^{6}$ The second is the agenda-setter model developed by Romer and Rosenthal (1978, 1979). In these models, an exogenously determined agenda-setter, on a one-dimensional issue, faces the constraint of a majority vote and can therefore only implement those policies that the median voter prefers to the status quo. The third is the pivotal politics model developed by Krehbiel (1998), a theoretical framework based on the idea that, for any particular issue, a pivotal voter (legislator) can be identified, and the final policy outcome hinges critically upon her preferences.

All of these approaches provide insights of significant value for understanding legislative politics, in the US and elsewhere. However, neither of these frameworks contain the level of institutional detail necessary to quantitatively interpret specific legislative settings, such as the dramatic period in 1933 after the landslide victory of FDR and the Democrats. Hence, we develop a new formal model of US Congress. In addition to the New Deal application, the model could be viewed as a starting point towards a formal theory of legislative politics and major reforms in the US, one that is institutionally richer than the existing models. ${ }^{7}$

What are then the most important institutional features of US legislative politics? Our highly subjective view is that the following features, ranked in order of deemed importance, are sufficient to give a good characterization of the formal institutional environment: (i) There are two chambers with different distribution of seats across states, and law-making follows a sequential procedure, with the House of Representatives moving before the Senate on spending bills, (ii) The President is elected nationally while Congress members are

\footnotetext{
${ }^{6}$ The original model by Baron and Ferejohn focuses on distributive politics with exogenous status quo, but the framework has been extended to spatial bargaining by Banks and Duggan (2000, 2006) and Cho and Duggan (2006), as well as to bargaining with endogenous status quo by, among others, Baron (1996) and Kalandrakis (2004). In addition, Merlo and Wilson (1995) introduced stochastic elements in the basic model of distributive politics.

${ }^{7}$ Krehbiel's (1998) framework contains more intitutional detail than the other models. However, it is different in purpose and lacks several of the features that we consider critical for the application in this paper. Still, we do think of the pivotal politics model as the work most closely related to the model developed here.
} 
elected by local constituencies (iii) Disagreements between the two chambers are resolved in a conference committee, (iv) The President has legislative veto power, (v) Committee and subcommittee chairs, as well as Congress members with formal "leadership positions" (such as the majority leader and the speaker of the House), can be quite influential and often have the power to stop legislation from happening, and (vi) There is a filibuster option in the Senate. To this, an informal institutional feature should be added: the fact that the President often, when it comes to major reform, functions as the de facto agenda-setter, despite not having such a role assigned constitutionally. ${ }^{8}$

While all being relevant, trying to include all of these institutional features in an estimable model proves to be very difficult. We model explicitly the first three of the listed features. In addition, we model the President as the agenda-setter. Including the fourth feature in the model would have no effect on the outcome. The two latter features are not formally modeled, as we believe them to be less important for understanding the nature of the spending allocation across broad regions. However, in particular the role of committees (v) is clearly an important feature in other settings. ${ }^{9}$ Furthermore, the role of influential individual legislators (leaders) could help with the interpretation of the allocation of spending at a more detailed regional level than is the focus of this paper. ${ }^{10}$

\subsubsection{Assumptions on Preferences}

When it comes to the preferences of the President and the Congress members, we make a number of simplifying restrictions. Perhaps most importantly, we assume that the decision to implement a program and the decision about the allocation of spending can be analyzed separately, and we do not explicitly analyze preferences over the generation of revenue. That is, we focus exclusively on the spending side of the New Deal, and therefore implicitly assume that any preferences that the President and the legislators might have had over the tax collection (and over budget deficit levels) did not interact with their preferences for the shape of the spending. This is a significant simplification, but one that is, at the very least, in line with the economic history literature on the topic.

Regarding the Congress members, we model them as "perfect representatives" of their

\footnotetext{
${ }^{8}$ Why the President often functions as the de facto agenda-setter, and when this is the case, are very important questions in their own right. Furthermore, these questions are not satisfactoraly answered by existing research, hence they provide interesting possibilities for future work.

${ }^{9}$ Committees have been analyzed extensively elsewhere. Among the most influential studies are Shepsle and Weingast (1987a, 1987b), Gilligan and Krehbiel (1987), Weingast and Marshall (1988) and Epstein and O'Halloran (1999). These studies, however, are typically focused on explaining the existence of committees, rather than predicting their effects.

${ }^{10}$ For instance, Wallis (1998) ascribes the large share of New Deal funds that went to Nevada to the influence of Key Pittman, President Pro Tempore of the Senate 1933-1940.
} 
constituencies, with preferences defined (only) over the allocation received by their states. Given the assumption that the size and shape of the spending can be analyzed separately, this still allows for the Congress members having (ideological) preferences regarding the size of public spending. It does mean, however, that once the size of the spending is determined, the legislators bargain only with the welfare of their own region in mind. Note that this is in line with the assumptions typically used in the legislative bargaining literature on distributive politics initiated by Baron and Ferejohn (1989). Furthermore, we view it to be in the spirit of Mayhew's (1974) now-classic conclusion that members of Congress are primarily driven by reelection concerns, and therefore seek a tight link to their own constituencies. Still, this is a restrictive assumption, and one that would be interesting to extend.

Since the parameters of the President's utility function are at the core of what is to be determined in our empirical analysis, the details of this utility function will be discussed more extensively both in the theoretical and empirical sections. For now, simply note that we allow for the welfare of all regions (citizens) to enter the President's utility function. This difference between the utility functions of the legislators and the President is meant to reflect the feature that the nationally elected President and the locally elected Congress members represent very different constituencies.

Given these assumptions about preferences and agenda-setting, our paper may be thought of as a model of an executive branch (or some other exogenously determined external player) with de facto agenda-setting power trying to implement a program. The executive faces an explicitly modeled "congressional constraint" generated by the need to reconcile the interests of legislators (with amending power) that represent different (and disjoint) constituencies. We do not claim that this representation captures everything that mattered during the implementation of the New Deal. However, we do believe that our setup captures many of the most important aspects that follow from the structure of Congress and the conflict of interest between the President and the legislators.

\subsubsection{Dividing the US into Regions}

Our model divides the country in three regions. This modeling choice is motivated by our view that in the 1930s this classification achieves a good balance between realism and tractability. States within each of the regions were quite homogeneous, especially at the political level, which makes it possible to associate regions of the country with voting blocs in the Congress. This will be discussed in greater detail later. For now, we simply want the reader to note that the model's division of the country into three regions is a result that follows from the characteristics of the US in the 1930s, and not an ad-hoc division imposed in order to simplify the theoretical analysis. 


\subsection{Formal Setup}

We model the allocation decisions within each type of program as a separate bargaining game. In this game, the President acts as an agenda setter and Congress determines the final division of a fixed amount of resources. The set of congressional players is given by three groups of states (regions): $\mathcal{I}=\{$ West, North, South $\}$. An outcome of the bargaining game is simply a division of a given amount of resources among the three regions $x=\left(x_{W}, x_{N}, x_{S}\right)$. The total amount of resources is normalized so that $\sum_{i} x_{i}=1$. Each group $i \in \mathcal{I}$ holds a fraction $q_{i}$ of the total seats in the House and a fraction $p_{i}$ of the seats in the Senate. We assume that no group has an absolute majority of seats in either chamber. In line with the description of congressmen's preferences, the utility function of region $i$ is given by:

$$
u_{i}(x)=x_{i} \forall i \in \mathcal{I}
$$

Unlike congressional players, we allow the President to hold arbitrary preferences over allocation of resources. We assume these preferences can be represented by a utility function

$$
f(x, t): \Delta^{2} \times \mathbb{R}^{3} \rightarrow \mathbb{R}
$$

where the vector $t=\left(t_{i}\right)_{i \in \mathcal{I}}$ represents the president's relative inclination to assigning resources to each of the regions. The only restriction we impose on $f(x, t)$ is continuity in $x$, for all $t$.

The timing of the game reflects the description of the most important steps in the legislative process. First, the President proposes a split of the total resources going into a particular program, where the split is denoted by $x \in \Delta^{2}$. The House then evaluates the proposal as follows: with an initial yes/no vote it determines whether to pass the bill on unchanged. This effectively requires two groups voting in favor of the President's proposal. If the proposal passes unchanged, the Senate takes on the proposal. Otherwise, a House member is randomly selected to renegotiate the allocation, by proposing an amendment $x^{\prime} \in \Delta^{2}$. Each member has the same probability of being recognized. Hence, groups are recognized to make a proposal with probabilities proportional to their shares of seats $q_{i}$ in the House. An amendment proposal is effectively a take-it-or-leave-it offer that one group of states makes to the rest of the chamber. The House votes on the proposed amendment, a positive vote resulting in the bill being passed on to the Senate, a negative vote implying the bill is scratched. The Senate follows a similar procedure, where the text approved by the House represents the initial proposal. The bargaining process in the Senate may yield a different outcome from that of the House because groups are represented in different propor- 
tions. If the Senate approves the initial proposal, then the outcome is directly implemented. However, if the Senate modifies the initial proposal, we model the outcome of bargaining in the Conference Committee as a convex combination of the House and Senate bills.

In more precise terms, the president's strategy set consists of all possible proposals. A strategy for a congressional player is a more complicated object. It consists of the following: (i) a mapping from proposals into a binary vote, (ii) a history independent amendment proposal and (iii) a function from amendments into binary votes. Note that congressmen are assumed to always vote for their preferred option, regardless of whether they could be pivotal.

\subsection{Theoretical Results}

Proceeding by backward induction, we first analyze the Senate bargaining subgame following the rejection of the House bill. At this stage, a senator is randomly selected an amender. When a bill $(x)$ coming from the House is introduced in the Senate, each congressional player $(i)$ compares her payoff from voting in favor of the bill $\left(x_{i}\right)$ to the expected gains from rejecting it. The extent of these gains is equal to the probability of a senator from her own group $i$ being selected as a proposer in the subsequent amending stage. We prove this formally in Proposition 1.

Proposition 1 Each group $i$ has a reservation utility in the Senate equal to its share of seats $\left(p_{i}\right)$.

Proof. Denote the bill that comes into the Senate by $x$. If the Senate modifies the bill to $x^{\prime}$, the outcome will be $\frac{x+x^{\prime}}{2}$, while it will be equal to $\frac{x+x}{2}$ if it doesn't. Therefore, at the amending stage, senators only care about the outcome of the Senate bargaining process. Since the Senator recognized to amend can make a take-it-or-leave it offer to the rest of the chamber, she can propose an allocation in which her group keeps the entire amount of resources. In this case group $i$ obtains a payoff of 1 , while it obtains a payoff of zero otherwise. The probability of being recognized is equal to the group's share of seats in the Senate $\left(p_{i}\right)$, which completes the proof.

In this model, no group is assumed to hold a majority of the seats in the Senate. It follows that the bills passed by the House that are also approved by the Senate are those in which at least two groups receive more than their continuation values.

The next step is to analyze the game in the House following a rejection of the President's proposal. A representative who is selected to propose holds all the bargaining power within the House. In effect, this amender chooses between two options: either propose an allocation 
that will be also approved by the Senate, or choose a proposal that will be amended in the Senate. The optimal choice in the former class consists of acquiring the support of the group with the lowest continuation value in the Senate to form a coalition. The best option in the latter class is to keep the entire amount of resources and let the Conference Committee determine the final bill. This leads to the following result:

Proposition 2 The proposer's payoff in the House is given by:

$$
\max \left\{1-\min _{j \neq i} p_{j}, \frac{1+p_{i}}{2}\right\} .
$$

Proof. Let $i$ be the representative chosen to amend the President's proposal. The maximum value group $i$ can achieve by proposing an amendment that will be approved by the Senate is $1-\min _{j \neq i} p_{j}$. In fact, all representatives will vote in favor of the amendment, while senators from groups $j \neq i$ will vote in favor only if $x_{j} \geq p_{j}$. Group $i$ then finds it optimal to acquire the support of the group with smallest senate delegation.

If group $i$ proposes an amendment that will not be approved by the Senate, the bill approved in the Senate is independent of what happens in the House. Let $x$ denote the proposed amendment. Therefore, group $i$ has an expected payoff of $p_{i}$ at the Senate stage and of $x_{i}$ at the House. The outcome of the Conference committee is simply $\frac{1}{2}(x+p)$. Hence, the amending representative will propose a bill $x$ which gives him the entire amount of resources in the house, thereby obtaining a payoff of $\frac{1}{2}\left(x_{i}=1\right)+\frac{1}{2}\left(x_{i}=p_{i}\right)$.

Furthermore, it turns out that the optimal strategy is always the same, i.e. independent of the amender's identity:

Proposition 3 For any distribution of seats, all Representatives propose an amendment that will be approved by the Senate.

Proof. For any $p \in \Delta^{2}$ such that $p_{i} \neq p_{j} \forall i, j$, it is the case that $1-\min _{j \neq i} p_{j}>\frac{1+p_{i}}{2}$. This can be shown by letting the proposer be a member of group $i$ and defining $p_{H}:=\max _{j \neq i} p_{j}$ and $p_{L}:=\min _{j \neq i} p_{j}$. The following inequalities can then be established: $1-\min _{j \neq i} p_{j}-\frac{1+p_{i}}{2}=$ $p_{i}+p_{H}-\frac{1}{2}-\frac{p_{i}}{2}=\frac{2 p_{H}-1+p_{i}}{2}=\frac{p_{H}+\left(1-p_{L}-p_{i}\right)-1+p_{i}}{2}=\frac{1}{2}\left(p_{H}-p_{L}\right)>0$.

That is, following rejection of the President's proposal, the group selected as an amender targets the group that holds the smallest share of seats in the Senate and offers its continuation value. We can now characterize the reservation utility of each group in the House.

Proposition 4 Let $q_{i}$ denote group $i$ 's share of seats in the House and $p_{i}$ its share of seats in the Senate. Let $p_{1}>p_{2}>p_{3}$. The three groups' reservation utilities in the House are 
given by:

$$
\begin{aligned}
& V_{1}=q_{1}\left(1-p_{3}\right) \\
& V_{2}=q_{2}\left(1-p_{3}\right)+q_{3} p_{2} \\
& V_{3}=\left(1-q_{3}\right) p_{3}+q_{3}\left(1-p_{2}\right) .
\end{aligned}
$$

Proof. Each group receives a payoff of $1-\min _{j \neq i} p_{j}$ when selected as an amender and $p_{i}$ when targeted by another group to form a coalition. Given the ordering of seats in the Senate, groups 1 and 2 target group 3, while group 3 targets group 2. Therefore, group 1 obtains a payoff of $\left(1-p_{3}\right)$ with probability $q_{1}$ and the reservation utilities of the other groups follow analogously.

Naturally, the allocations passing in the House are those that provide expected utility levels $E\left(x_{i}\right) \geq V_{i}$ for at least two of the three groups. Given these results, and using the composition of Congress in 1932, the set of proposals that would be approved unchanged can be drawn as follows:

Figure 1 here

Finally, we turn to the president's problem. Essentially, the president must choose between proposing an allocation that will either (i) pass untouched, (ii) be modified by the House, or (iii) be modified by the Senate. Furthermore, Proposition 3 shows that the president's proposal will not be modified by both chambers. With this in mind, we can show that an equilibrium exists.

Proposition 5 There exists an equilibrium of this game.

Proof. Let $x$ denote the President's proposal. Let the vectors

$$
\begin{aligned}
e_{i} & :=x \in \Delta^{2}:\left(x_{i}=1, x_{j \neq i}=0\right) \\
i & \in\{1,2,3\}
\end{aligned}
$$

represent the allocations assigning the entire amount of resources to region $i$. Denote by $s(x)$ the expected outcome following amendment of $x$ by the Senate and the Conference Committee. As described by Proposition 1, $s(x)$ represents a lottery among the outcomes $\left\{\frac{x+e_{1}}{2}, \frac{x+e_{2}}{2}, \frac{x+e_{3}}{2}\right\}$ with probabilities given by $\left\{p_{1}, p_{2}, p_{3}\right\}$ respectively. Finally, denote by $h(x)$ the expected amendment of proposal $x$ by the House. As described by Proposition 4 , for any bill $x, h(x)$ is represents a lottery among the outcomes $\left\{\left(1-p_{3}, 0, p_{3}\right),\left(0,1-p_{3}, p_{3}\right)\right.$, $\left.\left(0, p_{2}, 1-p_{2}\right)\right\}$ with probabilities $\left\{q_{1}, q_{2}, q_{3}\right\}$ respectively. Let $y(x)$ represent the (possibly 
random) outcome of the congressional bargaining game, as a function of the President's proposal. The function $y(x)$ is defined over three regions:

$$
y(x)=\left\{\begin{array}{cl}
x & \text { if } x \text { lies in a Passing region } \\
s(x) & \text { if } x \text { is modified in the Senate } \\
h(x) & \text { if } x \text { is modified in the House }
\end{array}\right.
$$

The existence of an equilibrium of this game is equivalent to the existence of a solution to the President's constrained optimization problem: $\max _{x} E[f(y(x), t)]$. The President's utility function is continuous, so it attains a maximum over a compact set. The idea of the proof is to compute the maximum of the president's utility over the three regions (Passing, Modified by the House, Modified by the Senate) and then select the highest of the three values. Let M-Senate (M-House) denote the set of proposals that are amended by the Senate (by the House).

To adopt this procedure, we must only ensure that the President ultimately selects an outcome from a closed set. Unfortunately, the Passing regions (the non-passing regions) are closed sets if and only if congress members vote in favor of (against) the President's proposal when indifferent. Therefore, let indifferent Congress members vote in favor of $x$ if and only if the following holds:

$$
\sup _{x \in \text { Passing }} f(x, t)>\max \left\{\sup _{x \in \text { M-Senate }} E[f(s(x), t)], E[f(h, t)]\right\} .
$$

This specification for Congress members' voting behavior allows us to obtain the following equilibrium strategy profile:

$$
x^{*}(t)=\arg \max _{x \in \text { Passing }} f(x, t) \text {. }
$$

Congress members vote in favor of $x$ if indifferent.

whenever (1) is satisfied and

$$
x^{*}(t)=\left\{\begin{array}{cl}
\underset{x \in \mathrm{M} \text {-Senate }}{\arg \max } E[f(s(x), t)] & \text { if } \sup _{x \in \mathrm{M} \text {-Senate }} E[f(s(x), t)]>E[f(h, t)] \\
x \in \mathrm{M} \text {-House } & \text { if } \sup _{x \in \text { M-Senate }} E[f(s(x), t)]<E[f(h, t)]
\end{array} .\right.
$$

Congress members vote against $x$ if indifferent

whenever (1) is not satisfied. In the former case, the President prefers to propose an allocation that would not be modified. In this case the passing regions are closed (hence compact) so 
that $f(\cdot, t)$ attains a maximum there. In the latter case, the President prefers to propose an allocation that would be modified, either in the House or in the Senate. In this case, the non-passing regions are closed. In both cases, continuity of the utility function and the assumption (1) - or its contrary - ensure that the President has no profitable deviations. This completes the proof.

Up to this point, we have only assumed continuity of the utility function $f(x, t)$. By introducing the additional assumption of strict concavity of $f(x, t)$ in $x$ for all $t$, we can establish a uniqueness result. ${ }^{11}$

Proposition 6 If the President's utility function is strictly concave, the equilibrium outcome of this game is also unique.

Proof. Under strict concavity, $x^{*}(t)$ is unique both in the Passing and the M-Senate regions. The equilibrium outcome (and not strategy profile) is therefore unique. The only source of ambiguity comes from the fact that if the President wishes to have the House modify his proposal, then he is indifferent among all proposals $x \in \mathrm{M}$-House.

Note that in our model, the strict concavity of $f(\cdot, t)$ implies that the President is riskand inequality- averse. We will make this assumption in the empirical section, and further discuss its implications there.

As a final comment on our formal model, we would like to stress that we view our approach to be in line with the view of scholar such as David Mayhew and Keith Krehbiel, who downplay the role of parties in US politics. ${ }^{12}$ Our empirical analysis does use a strong correlation between regions and parties, but the model is not one in which outcomes are necessarily driven by party politics. We strongly believe that this is the appropriate approach for the context of interest in this paper. We do not, however, try to make the claim that parties never matter. ${ }^{13}$

\section{States, Regions and Goals}

During the period of consideration, the US was divided in several ways that correlated with broad geographic regions. After careful consideration of the data, we believe that an appropriate simplification is to divide the country into a smaller number of regions. More

\footnotetext{
${ }^{11}$ Since the outcome of the bargaining in Congress is potentially random, strict quasi concavity of $f(x, t)$ would not guarantee uniqueness of the President's optimal strategy. In fact, the property of quasi concavity does not extend to lotteries. The stronger property of (strict) concavity, however, extends to lotteries.

${ }^{12}$ At least this is our reading of works such as Mayhew (1993) and Krehbiel (1998).

${ }^{13}$ For a criticism of the views of Krehbiel and Mayhew, and for a theory of party-based politics in the US, see Cox and McCubbins (2005).
} 
specifically, we believe that the optimal trade-off between simplicity and transparency on one hand, and realism on the other, is model with focus on three regions: the South, the North and the West. These regions differed significantly, both economically and politically, but the states were quite homogenous within each region. The maps in figures 2(a) and 2(b) display the assignment of states to regions, as well as the correlation between our classification and the political division of the country at that time.

In order to distinguish the different possible motivations behind the New Deal, or more specifically spending allocation, we model the objective function of the Roosevelt administration as a combination of concerns for (i) relief and recovery, (ii) fundamental reform and development, (iii) political productivity/reelection probability, and (iv) rewarding Democrats. In line with most previous work we label (i) and (ii) as "economic" and (iii) and (iv) as "political." These four possible concerns cover the different objectives that people in the aforementioned literatures on the New Deal have ascribed to the allocation of funds. With respect to the theoretical model, these different objectives enter the model through the vector $t$ in the President's utility function. We now proceed to first describe the three regions, then to explain how the characteristics of each region map into Roosevelt's utility function.

The first of the regions, the South, was the poorest region in the country during the period of the New Deal. This is best seen by looking at the level of economic activity, as reflected in retail sales (Figure 3(a)). Furthermore, the South was the least developed region of the country according to more general criteria, such as the illiteracy rate (Figure 3(b)). Hence, if fundamental reform and long-run development were the only considerations that went into the shaping of the New Deal, this region would have been the primary target of New Deal means.

In addition to being poor, all of the states in this region were Democratic and had voted largely in support of Roosevelt in the 1932 election. Furthermore, their support had been solid over the previous decades. Hence, one would expect that a partisan executive branch, with the objective of rewarding states in which it had received support, would have yet another reason (in addition to their economic/reform needs) to target the states in the South. However, these states were also so solid in their support for the Democratic party that any reelection motive behind the allocation of New Deal funds would have had to be to their disadvantage. Finally, given the lower level of manufacturing development, their actual drop in economic performance during the Great Depression was not as marked as the drop of the other regions. Hence, if the primary motive behind the New Deal was to provide short-term relief and/or recovery, this should also have shown up as a spending disadvantage for the Southern states. 
The second of the regions, the West, was also a largely Democratic region during the period of the New Deal implementation. Roosevelt won $58 \%$ of the popular vote in the West, and only four states had a significant republican representation in their congressional delegation. On the other hand, the states in the West were not nearly as solidly grounded in the Democratic camp as the states in the South. In fact, over the previous decades, support for the Democratic party in western states had been more volatile than anywhere else (Figure 3(d)). Hence, if the Roosevelt administration had political motives in mind when implementing the New Deal programs, one would expect the President to include the Western states both in attempts to reward its own base (and the Congress members from its party) and in attempts to secure electoral votes for coming elections. However, the states in the West were significantly richer and more developed than the states in the South, which implies that a New Deal that was primarily motivated by fundamental economic reform would not have paid particular attention to these states. Finally, we emphasize that whether programs aiming at immediate relief and recovery would have been to the advantage of the West or not depends on what kind of program we are focusing on. Though the West was not hit as hard as the Northeast in terms of manufacturing output, it did suffer a severe drop in agricultural output. This is illustrated in Figure 3(e), which shows the percentage of failing farmland in the different regions. Hence, spending on farming programs, would have provided relief and recovery in this region of the country. Furthermore, the West was in many ways a suitable target for public works programs, due to its low level of existing infrastructure and its availability of natural resources. (However, as described later, in the baseline estimations we are agnostic about the suitability of public works programs.) On the other hand, more general relief programs, targeted at parts of the country in which the manufacturing sector was hard-hit, were unlikely to have the states in the West as targets for provision of relief and recovery, given the lower level of manufacturing development compared to the Northern part of the country.

As figures 3(a) and 3(b) show, the third of the regions, the North, was also significantly richer and more developed than the South. Hence, in terms of need for fundamental reform and long-run development, one would not expect the New Deal programs to target the North. In addition, the North was largely Republican, so partisan concerns (i.e. a focus on Democratic states) would have added to the disadvantage of these states, in the sense of not being recognized and targeted for spending by the Presidential administration.

The Northern states did, however, have two characteristics that should have worked to their favor in the determination of the spending allocation. First of all, they were not solidly Republican; FDR narrowly lost many of these states and in addition their support for the Democratic presidential contender in the recent history had been very low. Hence a 
reelection-motivated FDR would have had incentives to target these states with the objective of building popularity for coming elections. In addition, the industrial North was particularly hard-hit by the drop in the manufacturing sector. This is reflected, for instance, in some early statistics, such as the 1930 unemployment rate (Figure 3(f)). Hence, if relief / recovery was the primary motivation behind the New Deal, we would expect to see programs providing general relief to have been targeted at the Northern states.

To summarize the previous description, we characterize the regions in Table 1.

Table 1 here

Note that the West (the North) is classified as being Hard-hit only as far as the agricultural (industrial) sector is concerned. Based on the characteristics above, we can assign goals to regions. In doing this, we allow money spent in a region to serve one or more of the administration's goals/motives. More importantly, we let the assignment of relief/recovery concerns to a given region depend on the type of program being considered. The assignment of goals to regions is summarized in Table 2.

Table 2 here

Here, we are agnostic about whether public works projects were used to provide relief/recovery, in addition to fundamental reform and long-run development, in the South. That is, we do include relief/recovery concerns for the South, in addition to the North and the West (who both experienced significant drops in different sectors).

\section{Description of the Data}

The empirical part of this study uses data collected by Fishback, Kantor and Wallis (2003) on the distribution of spending for the New Deal programs implemented immediately after Roosevelt's inauguration in 1933, during the so called "100 Days." In some extensions, we also use data from all the years 1933 to $1937 .^{14}$ Their original data, taken from the US Office of Government Reports (1940), is used for a more detailed (county-level) empirical study. We have aggregated their values, first to the state then to the regional level. The regional aggregation is done according to the assignment of states to regions shown in Figure 2(a).

\footnotetext{
${ }^{14}$ An alternative approach would be to include all of the New Deal programs directly in the baseline model. However, as the political and economic situations changed over time, we do not believe it would be appropriate to use a single model to describe all of the different subperiods simultaneously. Hence, we limit the main empirical work to the first " 100 days," which is the part of the New Deal for which our model should have the greatest explanatory power.
} 
In terms of direct/explicit relief, the two centerpieces of the Roosevelt administration's reconstruction efforts were the Federal Emergency Relief Act (FERA) and the Works Progress Administration (WPA). FERA passed in 1933 and was enacted to provide immediate grants to states for relief projects. WPA passed two years later, in 1935 (under the Emergency Relief Appropriation Act), with the purpose of providing public employment for people who were out of work. Given our focus on the "100 Days", we always include FERA (1933) in our estimations, whereas we only use WPA in some robustness checks.

In addition to FERA and WPA, in most but not all of our estimations we include in the general relief category loans from the Home Owners Loan Corporation (HOLC), set up in 1933 under the Home Owners Refinancing Act with the stated objective of lending to homeowners who were facing significant risk of defaulting on their mortgage, and insured loans given by the Federal Housing Administration (INS/FHA). ${ }^{15}$

Besides direct relief programs, the government used public works projects to provide relief through employment as well as through stimulation to the economy. Most importantly, the Public Works Administration (PWA) was set up in 1933, under the National Industrial Recovery Act. The PWA funded such diverse projects as airports, schools, hospital, warships, dams and bridges. Following Fishback, Kantor and Wallis, we distinguish these from general relief programs and classify them in separate category of "public works." 16

In addition to general relief and public works programs, we consider the farm programs enacted during the New Deal period as a separate category. These programs are sufficiently distinct from all the others to justify a separation. In this category, the two largest programs were the Agricultural Adjustment Act (AAA) and the Farm Credit Act (FCA), both passed in 1933. The former was enacted with the stated objective of providing immediate relief to farmers and paying subsidies to farmers for curtailing production of certain crops. The latter was intended to provide operating loans to farmers on a short-term credit basis. In addition to these two programs, a number of agencies with smaller funds, such as the Farm Security Administration and the Rural Electrification Administration, were established. As these were too small to change the estimation results, they are also omitted here.

The distributions of funds over the three regions, for the nine different programs described above, are reported in Table 3 .

Table 3 here

\footnotetext{
${ }^{15}$ In addition to these programs/agencies, the Civil Works Administration (CWA) falls in the category of "general relief." The distribution of funds of this administration were, however, small in comparison with the other programs. We did try to include CWA funds. As it had no no effect on the estimation results we have chosen not to include it here.

${ }^{16}$ Note that the activities of the PWA were divided into two different kinds of programs: federal programs and state-programs (and loans). The latter were matched with federal money but on the initiative of local authorities. We do not, however, separate these two programs in our empirical work.
} 


\section{Empirical Approach}

We now turn to the empirical task of estimating President Roosevelt's preferences based on the predictions of our political model and on the available data. Note, first of all, that the limited number of data points does not allow us to use the techniques from standard econometrics to obtain standard errors and perform hypotheses testing. (The baseline estimation specification has only seven observations.) That is, asymptotic theory and large number approximations is not appropriate. Instead, our approach can be viewed as a nonlinear least squares / minimum distance procedure that provides an intuitive characterization of the motives behind the spending allocations.

\subsection{Roosevelt's Preferences}

For the purposes of our empirical exercise, a more explicit form for the President's utility function (than the general form used in the theory section) has to be specified. Specifically, we assume the President's utility function is given by:

$$
f(x, t)=\prod_{i \in \mathcal{I}} x_{i}^{t_{i}} .
$$

That is, we assume Roosevelt's preferences can be represented by a Cobb-Douglas utility function with weight $t_{i}$ on each region. The main implication of using this particular functional form is that Roosevelt is assumed to be averse to extremely unequal allocations. This reflects the difference in criteria under which the President and Congress are elected, and the consequently different mandates they are given. It is unlikely that the President could have justified shutting down a large region of the country from receiving any federal aid. In addition, in 1933 FDR presented himself as a paternal, nationally uniting figure in a time of crisis. In this context, we believe it makes sense to assume that he would have wanted to target every region with at least some federal funds.

In order to relate the President's taste parameters for each region to the various objectives he could pursue through the allocation of the funds, let $\alpha, \gamma, \delta$ and $\phi$ represent the weights that he assigns to the goals of political productivity, rewarding, relief/recovery and reform, respectively. The President's preferences are then defined over the shares assigned to each group, weighted by population size and the parameters pertaining to the each group's characteristics. More specifically, the weights in the President's utility function are given by $t_{i}=c_{i} N_{i}$. And if one lets $\boldsymbol{I}$ denote the indicator function, the parameters $c_{i}$ can be expressed as:

$$
c_{i}=\left[\boldsymbol{I}_{(\mathrm{i} \in \text { Productive })} \alpha+\boldsymbol{I}_{(\mathrm{i} \in \text { Democrat })} \gamma+\boldsymbol{I}_{(\mathrm{i} \in \text { HardHit })} \delta+\boldsymbol{I}_{(\mathrm{i} \in \text { Poor })} \phi\right] .
$$


Therefore, the assignment of different weights to each of the regions reflects the previous classification. Note that different regions are considered hard hit depending on the type of programs targeting them. These additional assumptions on the President's utility function allow us to obtain two further results in characterizing the equilibrium of the political model.

Corollary 7 The President's ideal allocation in the absence of political constraints is given by:

$$
x_{i}^{*}=\frac{c_{i} N_{i}}{\sum_{j \in \mathcal{I}} c_{j} N_{j}} .
$$

Proof. Straightforward from the utility maximization problem on the simplex.

Note that if the President's preference parameters $c_{i}$ were identical for all regions, he would equalize per capita spending. In addition, if the allocation $x^{*}$ lies in a Passing region of the simplex, it also constitutes the unique prediction of our model.

Corollary 8 The President always proposes an allocation that is approved by the House.

Proof. Any allocation resulting from the amendment process in the House assigns no resources to one of the regions. Under Cobb-Douglas utility, these allocations achieve the lower bound on the President's utility.

In Appendix A, we present some examples that show how the President's preferences over economic and political goals map into proposed allocations. In the following sections, we use these results together with the historical evidence to devise the following empirical procedure.

\subsection{Estimation Strategy}

The main goal of the empirical approach is to identify the parameter values of the President's objective function that provide the best fit of the model's predicted allocations to the observed data. We define theoretical allocations as our model's predicted allocations, a function of the President's preferences and the outcome of the President-Congress bargaining game. Note that under the Cobb-Douglas utility function assumption, the equilibria of our model can lead to three very different types of outcomes: (i) the immediate approval of bills that implement FDR's ideal allocation, (ii) the immediate approval of bills that implement a Congress-constrained allocation different from FDR's ideal allocation, (iii) the approval of bills that pass untouched through the House but are radically amended in the Senate. Discerning between the three types of outcomes in the data is a key step. 
In the actual empirical work, we start by plotting the allocations in the simplex representing the outcomes of the bargaining game. This is shown in Figure 4.

Figure 4 here

We observe that only one of these observations lies in a "passing region" (which would lead to type (i) outcomes), and then exploit the historical fact that during the "100 Days" Congress did not amend FDR's proposals substantially. ${ }^{17}$ This rules out type (iii) outcomes. Combining these two facts, we conclude that each observed allocation must correspond to a type (ii) outcome. In other words, we conjecture that Roosevelt was aware that his ideal allocations were politically infeasible and that his proposals took congressional constraints into account. Therefore, the observations must be generated from allocations approved by Congress that lie along one or more constraints. We attribute any differences between the observed allocations and the (theoretical) congressional constraints to "execution error" by the federal agencies through which the funds were distributed. ${ }^{18}$

Identifying the relevant binding constraints is the hardest task in this approach. To this end, note the division of programs into General Relief, Public Works and Farming. For each program type, we select the constraint closest to the observed allocations and conjecture it was the binding congressional constraint. We then construct the theoretical allocation for each group of programs separately, as the equilibrium of the model under the type's conjectured congressional constraint.

Having determined (conjectured) which constraints that were the binding ones, we proceed to the actual derivation of the model's parameters. This is done with a minimum distance approach. Formally, the parameter estimates are given by the solution to the following problem:

$$
\begin{aligned}
& \min _{\alpha, \gamma, \delta, \phi} \sum_{i=1}^{K} w_{i}\left\|x_{i}^{O B S}-x_{i}^{T H E O R Y}\right\|^{2} \\
& \text { s.t. }(\alpha, \gamma, \delta, \phi) \geq(0,0,0,0) \\
& \text { s.t. } \alpha+\gamma+\delta+\phi=1
\end{aligned}
$$

\footnotetext{
${ }^{17}$ For instance, according to Patterson (1967, page 3): "the passage of eleven key bills in 1933 took only a total of forty hours of debate in the House. The legislative process in the Senate was a bit more careful but still not slow."

${ }^{18}$ By these means we allow - and indeed we find - these "errors" not to have a zero mean. Not surprisingly, the observed allocations are often closer to FDR's estimated ideal points. Note that this does not affect the Congressional bargaining game described above. It simply means that FDR, or agencies with similar objectives as FDR, probably had some ex-post influence over the spending.
} 
where $w$ is a $K$-dimensional vector of weights containing the total size of each of the programs considered and $x^{T H E O R Y}$ is the vector corresponding to Roosevelt's ideal point under the intuitive conjecture that the Western senators constrained the allocation of General Relief programs and that the Southern representatives constrained all other programs.

Finally, once we have obtained a vector of parameter estimates, we perform a number of simple checks (though not hypothesis tests in the traditional econometric sense) of the internal consistency of the results and the tightness of the parameter estimates. First and foremost, after estimating the preference parameters, we make an attempt to falsify the conjecture about slack vs. binding constraints, using the estimation results. Given the estimated parameter values, we can easily compute FDR's ideal allocations. Then, under the conjecture of Congress-constrained allocations, if any of FDR's ideal allocations lie in the passing regions, our conjectured equilibrium is falsified by the data.

Obviously, for each conjectured combination of binding vs slack constraints, we can at most use this test to conclude that the data does not falsify the model. Clearly, this does not mean that the test will necessarily reject a false model. Nevertheless, we try a number of alternative assumptions about which constraints (if any) were actually binding, and seek to obtain non-falsifiable conjectures. To preview the results: the above described baseline conjecture (regarding which constraints that bind) turns out to be the only conjecture passing the consistency test.

\subsection{Baseline Estimation Results}

The baseline estimation considers the levels of the allocation of funds in the seven New Deal programs passed during the "100 Days". In the criterion function, each program is weighted by its total size. As a theoretical allocation, we consider a scenario in which FDR's distribution of general relief funds is constrained by the West in the Senate whereas the allocations of farming and public works funds are both constrained by the South in the House. The parameter estimates delivered by this procedure are reported in Table 4.

Table 4 here

These estimates allow us to compute FDR's ideal allocations. The ideal allocations can be viewed as a counterfactual experiment, in which the following question is asked: How different would the distribution of funds have looked if the executive branch (FDR) had been unconstrained in the implementation of new government programs? Note, for instance, the implication that FDR would have liked to give a greater share of the general relief programs to the North, had he not been constrained by the West. 
Finally, in order to perform a falsification test, we derive the predictions that follow from our estimated parameters, but with Roosevelt constrained. The ideal allocations and the predictions of the constrained model are reported in Table 5.

\section{Table 5 here}

These allocations differ from the observations by an average of 0.0582 . More importantly, the conjectured scenario in which these constraints (West in the Senate for general relief

programs, South in the House for the other programs) are binding is the only one under which our estimated ideal allocations would not pass through Congress untouched. In other words, our baseline conjecture is the only one in which the conjectured congressional constraints can not be falsified jointly by the data and the parameter estimates. We take this as a check of the internal consistency of the model.

\subsection{Robustness Checks}

Our baseline specification (reprinted as BASE in Table 6) considers the levels of the seven observed allocations separately. We now proceed to operate a series of robustness checks by means of estimating our parameters under several different specifications of the PresidentCongress bargaining game.

\subsubsection{Minor Changes to the Estimation Approach}

In this part, we present the results of several minor changes to the estimation execution. First and foremost, we estimate the model including all the nine programs (L9). We then test for congressional logrolling. Specifically, this means that we treat all allocations from any given type of program passed in the same year as a unique bill, which leaves us with five observations. The result of this estimation is displayed in the row labeled L5. Finally, instead of assigning different weights to different programs based on their size (in total spending), we estimate the parameters assigning equal weights to all of the nine baseline program programs. The results of this exercise are labeled L9uw in Table 6.

\subsubsection{Program-Specific Bargaining Powers}

In the next three robustness checks (R9, R5, R9UW), we give a different interpretation to our structural error. Here, we acknowledge that our model's constraints can only represent with approximation the bargaining powers in place in Congress during the New Deal. Moreover, by requiring the President to obtain the support of two large congressional players, we are 
de facto ruling out the possibility of building smaller majority coalitions. In reality, by targeting only part of the states in a given region, FDR could potentially tend less to that region's interest and propose an allocation that is closer to his ideal point. Certainly, the historical evidence does suggests that FDR's proposals passed with large support. However, it is still possible that some of the bills' crafting and actual bargaining took place outside of the formal sessions of the Congress, implying that the voting record in Congress do not fully capture the shape of the real coalitions behind the bills. Hence, we believe that an alternative specification, with a less precise interpretation of the constraints, is a useful exercise.

More specifically, while maintaining the same conjecture regarding which constraints were binding, we now assume that the politically constraining regions received exactly what was necessary in each session to win their support. This is equivalent to assuming that, for each program, the congressmen from the constraining region were able to correctly predict the final allocation and required exactly what they eventually received in order to vote in favor of the program. Note that this is consistent with the idea that, for all the programs where the observed allocations do not fall in theoretical "passing regions" (as given in Figure 1), FDR might have passed the bills with smaller winning coalitions than those implied by the baseline approach.

With this approach, the ratio between the shares of any two regions is independent of the share received by the third one (a consequence of the Cobb-Douglas assumption imposed on the President's preferences). Together with the assumption that the observed allocations directly deliver the binding constraint for each program, this implies that we are able to estimate FDR's preference parameters on the basis only of the ratios of the allocations received by the non-constraining regions.

We carry out this estimation approach for all programs separately and also under our logrolling specification (R5 in Table 6). Finally, we perform the estimation placing equal weights on all nine programs (R9UW). The resulting parameter estimates are very similar to the case of varying weights. This works as a confirmation of the relative homogeneity of approved allocations across the three types of programs, which is already evident from the data.

To summarize the results of different empirical procedures, we are quite confident that our estimates lie within the bounds reported in Table 6. These preliminary estimates indicate that economic concerns, in particular providing relief/recovery, were the primary motives behind the New Deal. Political motives were also existent, but less important. 


\section{Concluding Discussion}

In this paper, we develop a formal model of bargaining in the US Congress and apply the model to the spending decisions of 1933 during the so-called "100 Days," in hope of improving our understanding of the objectives behind the implementation of the New Deal. In the theoretical model, the distribution of government funds over regions of the country is the outcome of a bargaining game, in which the President acts as the agenda-setter (proposer) and Congress bargains over the final shape of the spending bill. We take into account the two-chamber structure of the Congress, and explicitly model the sequential nature of the legislative process, with the House of Representatives acting before the Senate. Furthermore, we assume that both the Congress members and the President are sequentially rational.

For any given set of preference parameters (in the President's utility function) and any given distribution of seats in the Congress, we can solve the model for a unique predicted outcome, i.e. a unique predicted distribution of funds across regions. This allows us to use the actual distributions of New Deal funds to estimate the preference parameters of the Roosevelt administration. We link theory to data and estimate the model's parameters using a simple minimum distance approach. That is, we estimate Roosevelt's preference parameters by minimizing a weighted distance between the actual distributions and the theoretical (model) expressions characterizing the equilibrium. The limited number of data points implies the standard econometric approach (asymptotic theory) for deriving standard errors and hypotheses tests is not appropriate. Hence, we are unable to assess the "tightness" of our estimated parameter values. Instead, as a robustness check, we estimate a number of different versions of the model, controlling for possible logrolling and misspecifications of the constraints imposed on Roosevelt by the 73rd Congress. In addition, we discuss and apply some more "conceptual tests" - ways in which parameter estimates could be falsified due to internal incoherences of the model. Our baseline estimation pass these falsification tests.

The baseline parameter estimates indicate that the motivation behind the New Deal was primarily economic, but that political concerns do seem to have existed as well. All of the robustness checks give a similar and reasonably coherent picture. In particular, all the specifications deliver estimates that imply a significantly greater concern for relief/recovery (one of the two motives labeled as "economic") than for any other motive. Regarding the other possible motives, political productivity (reelection concerns) appears to have been of lesser importance. The relative relevance of concerns for fundamental reform vs. reward for democratic states is unclear, as it varies across specifications. Neither of these motives, however, appears to have been as important as relief/recovery. Taken together, this is broadly in line with what we perceive to be the general message of the body of research by John 
Wallis: that economic concerns for relief and recovery, though not necessarily for fundamental reform and development, largely drove the New Deal, and that purely "political" concerns mattered but more on the margin.

We would like to stress that this paper should be viewed as a complement to the existing work on the objectives of the New Deal. Our formal approach has the advantage of delivering precise meaning to the estimated parameters. However, this comes at the obvious cost of reducing the richness of the model's institutional setting, in comparison with previous research. We can only explain the part of the spending that was determined by the President and Congress. and we do not capture preferences over the tax collection or budget deficit necessary to fund the spending programs (though this is a simplification we share with most previous research). In addition, the aggregation of states into regions implies we have nothing to contribute to the analysis of the local (intra-region) distribution of funds.

While recognizing these limitations, we do believe that there is scope for further research that could extend this paper in several ways. In particular, although we do perform a number of robustness checks controlling for different forms of logrolling, we do not explicitly model how (whether) funds from one type program could be used by the President to relax constraints for a different program. To do that would require introducing additional dynamic features to account for the sequential nature multiple bills, and issues of credibility would become central. We consider this extension very interesting, as it would provide a general model that could be used to analyze political logrolling. However, it would also introduce significant additional modeling complexity, and would necessarily shift the focus away from the empirical / historical aspects of this research project. Hence, it falls outside the scope of this paper, which is meant to be applied with focus on the New Deal period.

\section{References}

[1] Anderson, Gary M., and Tollison, Robert D. (1991), "Congressional Influence and Patterns of New Deal Spending." Journal of Law EG Economics, Vol. 34: 161-175.

[2] Banks, Jeffrey S. and John Duggan (2000), "A Bargaining Model of Collective Choice," American Political Science Review, Vol. 94: 73-88.

[3] Banks, Jeffrey S. and John Duggan (2000), "A General Bargaining Model of Legislative Policy-Making." Quarterly Journal of Political Science Vol.1: 49-85.

[4] Baron, David and John Ferejohn (1989), "Bargaining in Legislatures," American Political Science Review, Vol. 83: 1181-1206. 
[5] Baron, David (1996), "A Dynamic Theory of Collective Goods Programs," American Political Science Review, Vol. 90: 316-330.

[6] Bernstein, Barton J. (1968), "The New Deal: The Conservative Achievements of Liberal Reform" in Barton J. Bernstein (ed.) Towards a New Past: Dissenting Essays in American History, Pantheon Books.

[7] Besley, Timothy (2004), "Paying Politicians: Theory and Evidence," Journal of the European Economic Association, Vol. 2-3: 193-215.

[8] Besley, Timothy (2006), Principled Agents? The Political Economy of Good Government, Oxford University Press.

[9] Callander, Steve (2005), "Political Motivations," Working Paper, Northwestern University.

[10] Cho Seok-Ju and John Duggan (2003), "Uniqueness of stationary equilibria in a onedimensional model of bargaining," Journal of Economic Theory, Vol. 113 (1):118-130.

[11] Cole, Harold L. and Lee E. Ohanian (2004), "New Deal Policies and the Persistence of the Great Depression: A General Equilibrium Analysis," Journal of Political Economy, Vol. 112: 779-816.

[12] Cox, Gary W. and Matthew D. McCubbins (2005), Setting the Agenda : Responsible Party Government in the U.S. House of Representatives, Cambridge University Press.

[13] Epstein, David and Sharon O'Halloran (1999), Delegating Powers : A Transaction Cost Politics Approach to Policy Making under Separate Powers, Cambridge University Press.

[14] Eraslan, Hulya and Antonio Merlo (2002), "Majority Rule in a Stochastic Model of Bargaining," Journal of Economic Theory, Vol.103: 31-48.

[15] Fishback, Price V., Shawn Kantor and John J. Wallis (2003) "Can the New Deal's three Rs be rehabilitated? A program-by-program, county-by-county analysis," Explorations in Economic History, Vol. 40: 278-307.

[16] Fleck, Robert K. (1999), "Electoral Incentives, Public Policy, and the New Deal Realignment." Southern Economic Journal Vol: 65: 377-404.

[17] Fleck, Robert K. (2001), "Inter-Party Competition, Intra-Party Competition, and Distributive Policy: A Model and Test Using New Deal Data." Public Choice, Vol: 108: $77-100$. 
[18] Flynn, John T. (1944), As We Go Marching, Doubleday, Doran and Company.

[19] Gilligan, Thomas W. and Keith Krehbiel (1987), "Collective Decision-Making and Standing Committees: An Informational Rationale for Restrictive Amendment Procedures," Journal of Law Economics and Organization, Vol. 3 (2): 287-335.

[20] Knight, Brian (2004), "Parochial Interests and the Centralized Provision of Local Public Goods: Evidence from Congressional Voting on Transportation Projects," Journal of Public Economics, Vol. 88(3-4): 845-866.

[21] Knight, Brian, (2005), "Estimating the Value of Proposal Power," American Economic Review, Vol. 95(5): 1639-1652.

[22] Krehbiel, Keith (1998), Pivotal Politics: A Theory of U.S. Lawmaking, University Of Chicago Press.

[23] Libecap, Gary (1998), "The Great Depression and the Regulating State: Federal Government Regulation of Agriculture, 1884-1970," in Michael D. Bordo, Claudia Goldin and Eugene N. White, The Defining Moment: The Great Depression and the American Economy in the Twentieth Century, University of Chicago Press.

[24] Mayhew, David (1974), Congress : The Electoral Connection, Yale University Press.

[25] Mayhew, David (1993), Divided We Govern : Party Control, Lawmaking, and Investigations, 1946-1990, Yale University Press.

[26] Merlo, Antonio and Charles Wilson (1995), "A Stochastic Model of Sequential Bargaining with Complete Information," Econometrica, Vol. 63: 371-399.

[27] Patterson, James T. (1967), Congressional Conservatism and the New Deal: The Growth of the Conservative Coalition in Congress, 1933-1939, University of Kentucky Press.

[28] Powell, Jim (2003), FDR's Folly, How Roosevelt and His New Deal Prolonged the Great Depression, Crown Forum.

[29] Reading, Don C. (1973), "New Deal activity and the states, 1933 to 1939," Journal of Economic History, Vol. 33: 792-810.

[30] Romer, Thomas and Howard Rosenthal (1978), "Political Resource Allocation, Controlled Agendas, and the Status Quo," Public Choice, Vol. 33: 27-43. 
[31] Romer, Thomas and Howard Rosenthal (1979), "Bureaucrats versus Voters: On the Political Economy of Resource Allocation by Direct Democracy," Quarterly Journal of Economics, Vol. 93 (4): 563-587.

[32] Rubinstein, Ariel (1982), "Perfect Equilibrium in a Bargaining Model," Econometrica, Vol. 50: $97-110$.

[33] Shepsle, Kenneth A. and Barry R. Weingast (1987b), "The Institutional Foundations of Committee Power," American Political Science Review, Vol. 81: 85-104.

[34] Shepsle, Kenneth A. and Barry R. Weingast (1987a), "Why are Congressional Committees Powerful," American Political Science Review, Vol. 81: 935-45.

[35] Strömberg, David (2004), "Radio's Impact on Public Spending," Quarterly Journal of Economics, Vol. 119: 190-221.

[36] US Office of Government Reports, Statistical Section (1940). Report No. 10, volume 1, County reports of estimated federal expenditures, March 4, 1933-June 30, 1939.

[37] Wallis, John J. (1984), "The birth of the old federalism: financing the New Deal, 19321940," Journal of Economic History, Vol. 44: 139-159.

[38] Wallis, John J. (1985) "Why 1933? The Origins and Timing of National Government Growth 1933-1940," Research in Economic History, Vol. 8: 139-159.

[39] Wallis, John J. (1998), "The political economy of New Deal spending revisited, again: with and without Nevada," Explorations in Economic History, Vol. 35: 140-170.

[40] Weingast, Barry R. and William J. Marshall (1988), "The Industrial Organization of Congress; or, Why Legislatures, Like Firms, Are Not Organized as Markets," Journal of Political Economy, Vol. 96 (1): 123-163.

[41] Wright, Gavin (1974), "The political economy of New Deal spending: an econometric analysis," Review of Economics and Statistics, Vol. 56: 30-38.

[42] Zinn, Howard (1966), New Deal Thought, Bobbs-Merrill. 


\section{A Examples}

The following numerical examples illustrate the outcomes of the President-Congress bargaining game under different assumptions on the President's preferences. In particular, we maintain the composition of Congress in 1932 and consider the two cases in which the President pursues only economic goals (reform, recovery) and political goals (productivity, reform) respectively.

\section{A.1 Economic Goals}

Suppose the President is equally interested in reform and recovery but completely uninterested in politics. In our model's terminology, this is equivalent to assuming $\alpha=\gamma=0$ and $\delta=\phi=\frac{1}{2}$. As an example, consider a general relief program, such as unemployment benefits. the President's ideal allocation in this case would be given by

$$
\begin{aligned}
x_{W}^{*} & =0 \\
x_{N}^{*} & =\frac{N_{N}}{N_{N}+N_{S}}=.57 \\
x_{S}^{*} & =\frac{N_{S}}{N_{N}+N_{S}}=.43
\end{aligned}
$$

and it would pass since both $x_{N}$ and $x_{S}$ exceed $\max \left\{V_{N}, p_{N}\right\}$ and $\max \left\{V_{S}, p_{S}\right\}$ respectively.

Now, consider the case of a farming program. the President's ideal allocation is given by

$$
\begin{aligned}
x_{W}^{*} & =\frac{N_{W}}{N_{S}+N_{W}}=.45 \\
x_{N}^{*} & =0 \\
x_{S}^{*} & =\frac{N_{S}}{N_{S}+N_{W}}=.55
\end{aligned}
$$

This allocation would also pass, though supported by a different majority coalition.

Finally, for public works programs the President's ideal allocation would be given by

$$
\begin{aligned}
x_{W}^{*} & =\frac{N_{W}}{2 N_{S}+N_{W}+N_{N}}=.20 \\
x_{N}^{*} & =\frac{N_{N}}{2 N_{S}+N_{W}+N_{N}}=.32 \\
x_{S}^{*} & =\frac{2 N_{S}}{2 N_{S}+N_{W}+N_{N}}=.48
\end{aligned}
$$

This allocation would pass in the House since both the West and the South would endorse 
it, and it would pass in the Senate, supported this time by the North and the South. Hence, we can conclude that an economic President would see the ideal allocations pass, and these ideal allocations would be given by the expressions above.

\section{A.2 Political Goals}

In this example, we suppose that the President only cares about political productivity and

rewarding Democratic states. Formally, let $\alpha=\gamma=\frac{1}{2}$ and $\delta=\phi=0$. Then for general relief programs, the President's ideal allocation is

$$
\begin{aligned}
x_{W}^{*} & =\frac{2 N_{W}}{2 N_{W}+N_{N}+N_{S}}=.19 \\
x_{N}^{*} & =\frac{N_{N}}{2 N_{W}+N_{N}+N_{S}}=.59 \\
x_{S}^{*} & =\frac{N_{S}}{2 N_{W}+N_{N}+N_{S}}=.22
\end{aligned}
$$

Only the North's representatives would support this allocation, which would be therefore rejected by the House. As a consequence, the President would choose to "buy off" the South in the House and the North in the Senate, by proposing the following allocation:

$$
\begin{aligned}
x_{W}^{*} & =\left(1-V_{S}-p_{N}\right)=.35 \\
x_{N}^{*} & =p_{N}=.29 \\
x_{S}^{*} & =V_{S}=.36
\end{aligned}
$$

In this case, the ideal and constrained optimal allocations for public works and farming programs would be identical. In fact, these programs only differ with respect to the economic relief component, which receives zero weight in the current formulation of the President's preferences.

Formally, one needs to verify that FDR prefers this allocation to other constrained allocations close to his ideal point. It can be shown, for instance, that he would obtain a lower utility were he to "buy off" only one region. 


\begin{tabular}{lccc}
\hline Characteristic & South & West & North \\
\hline Poor & $\checkmark$ & & \\
Hard-hit & & $\checkmark^{a}$ & $\checkmark^{i}$ \\
Potential swing-state & & $\checkmark$ & $\checkmark$ \\
Democratic in previous election & $\checkmark$ & $\checkmark$ & \\
\hline
\end{tabular}

Note: $a=$ agricultural sector, $i=$ industrial sector.

Table 1: Regional Characteristics

\begin{tabular}{lccc}
\hline Administrations' Concerns & South & West & North \\
\hline Reform/Development & $\checkmark$ & & \\
Relief and Recovery & $\checkmark^{p}$ & $\checkmark^{p, f}$ & $\checkmark^{r, p}$ \\
Productivity/Reelection & & $\checkmark$ & $\checkmark$ \\
Partisanship/Rewarding & $\checkmark$ & $\checkmark$ & \\
\hline Note: $p=$ public works programs, $f=$ farming, $r=$ general relief
\end{tabular}

Table 2: Goals and Regions

\begin{tabular}{llccccc}
\hline & & & & \multicolumn{3}{c}{ Region Shares } \\
\cline { 5 - 7 } Program Name & Program Type & Year & Total Funds & North & South & West \\
\hline FERA & General Relief & 1933 & 2.7 & .50 & .20 & .30 \\
WPA & General Relief & 1935 & 6.2 & .54 & .19 & .28 \\
HOLC & General Relief & 1933 & 3.1 & .54 & .19 & .28 \\
INS/FHA & General Relief & 1934 & 2.7 & .45 & .20 & .35 \\
PWA, Federal & Public Works & 1933 & 0.8 & .41 & .24 & .35 \\
PWA, Match 1 & Public Works & 1933 & 0.6 & .41 & .34 & .23 \\
PWA, Match 2 & Public Works & 1933 & 1.4 & .44 & .25 & .32 \\
AAA & Farming & 1933 & 2.0 & .03 & .43 & .49 \\
FCA & Farming & 1933 & 1.3 & .12 & .32 & .56 \\
\hline
\end{tabular}

Note: Total Funds are in billions of dollars (1932).

Table 3: Program Details 


\begin{tabular}{cccc}
\hline \multicolumn{2}{c}{ Politics } & \multicolumn{2}{c}{ Economics } \\
\hline Productivity $(\alpha)$ & Rewarding $(\gamma)$ & Recovery $(\delta)$ & Reform $(\phi)$ \\
\hline 0.1120 & 0.0920 & 0.6029 & 0.1931 \\
\hline
\end{tabular}

Table 4: Baseline Parameter Estimates

\begin{tabular}{ccccccc}
\hline & \multicolumn{3}{c}{ Ideal Allocations } & \multicolumn{3}{c}{ Predicted Allocations } \\
\cline { 2 - 7 } Program Type & North & South & West & North & South & West \\
\hline Relief & 0.6739 & 0.2055 & 0.1206 & 0.4598 & 0.1402 & 0.4000 \\
Farming & 0.1339 & 0.2607 & 0.6054 & 0.1159 & 0.3600 & 0.5241 \\
Pub.Works & 0.3762 & 0.3574 & 0.2663 & 0.3747 & 0.3600 & 0.2653 \\
\hline
\end{tabular}

Table 5: Ideal and Predicted Allocations

\begin{tabular}{lcccccccccc}
\hline & \multicolumn{10}{c}{ Percentage Weight Estimates } \\
\cline { 2 - 11 } Goals & Base & L9 & L5 & L9uw & Base & L9 & R5 & R9uw & min & max \\
\hline Productivity & 11.20 & 11.07 & 15.39 & 10.68 & 9.24 & 9.76 & 12.63 & 9.64 & 9.24 & 15.39 \\
Rewarding & 9.20 & 9.18 & 8.68 & 9.27 & 9.60 & 11.57 & 12.35 & 10.02 & 8.68 & 12.35 \\
Recovery & 60.29 & 60.51 & 55.90 & 59.93 & 54.45 & 57.28 & 57.35 & 56.85 & 54.45 & 60.51 \\
Reform & 19.31 & 19.24 & 20.03 & 20.12 & 22.49 & 21.39 & 17.67 & 23.49 & 17.67 & 23.49 \\
& & & & & & & & & & \\
Total & 7 & 9 & 9 & 9 & 7 & 9 & 9 & 9 & & \\
Criterion & L & L & L & L & R & R & R & R & & \\
Weights & YES & YES & YES & NO & YES & YES & YES & NO & & \\
\hline
\end{tabular}

Note: $\mathrm{L}=$ Levels of allocations $; \mathrm{R}=$ Program-Specific Bargaining Powers

Table 6: Estimation Results 


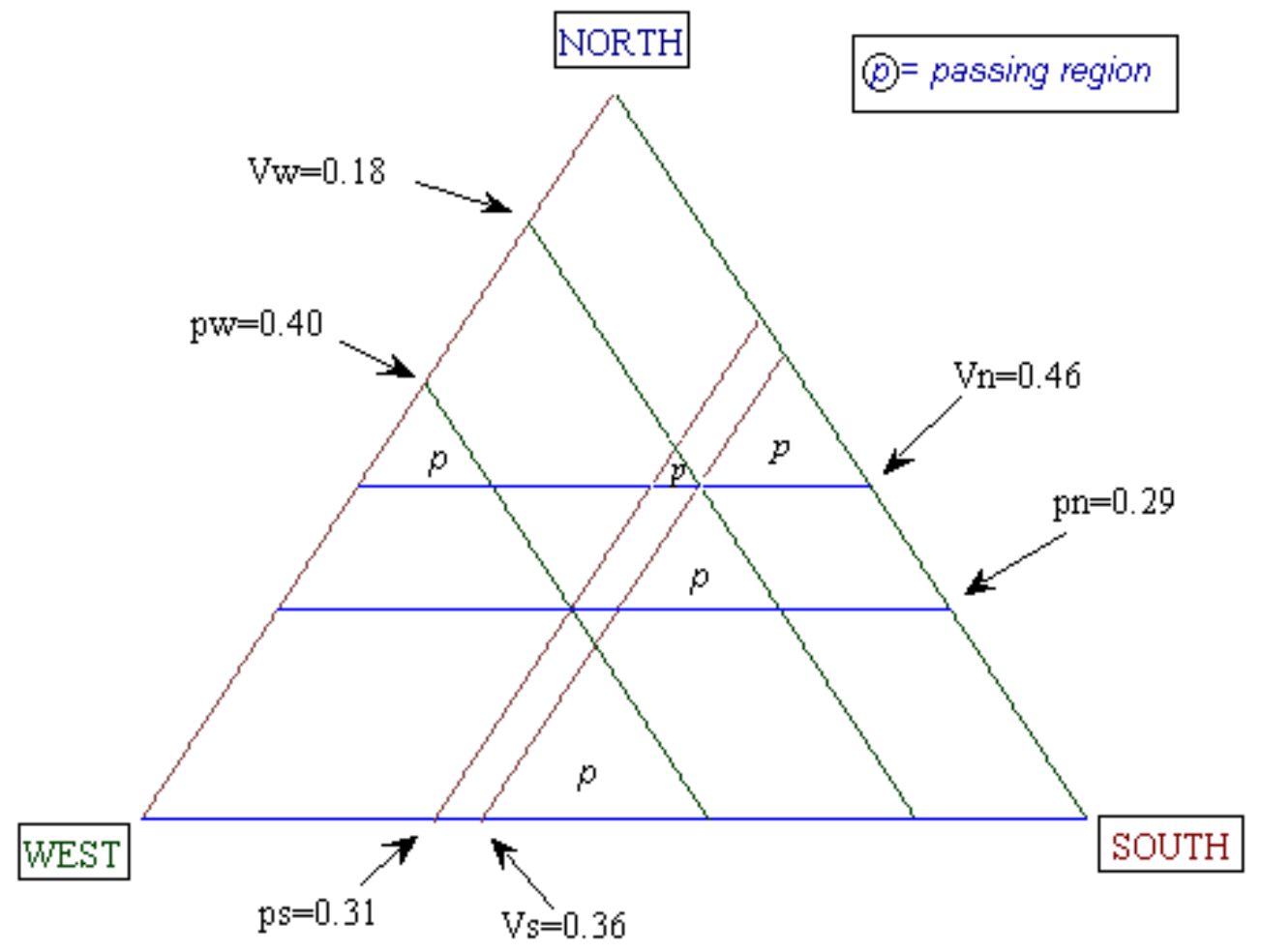

Figure 1: Bargaining Outcomes and Congressional Constraints 


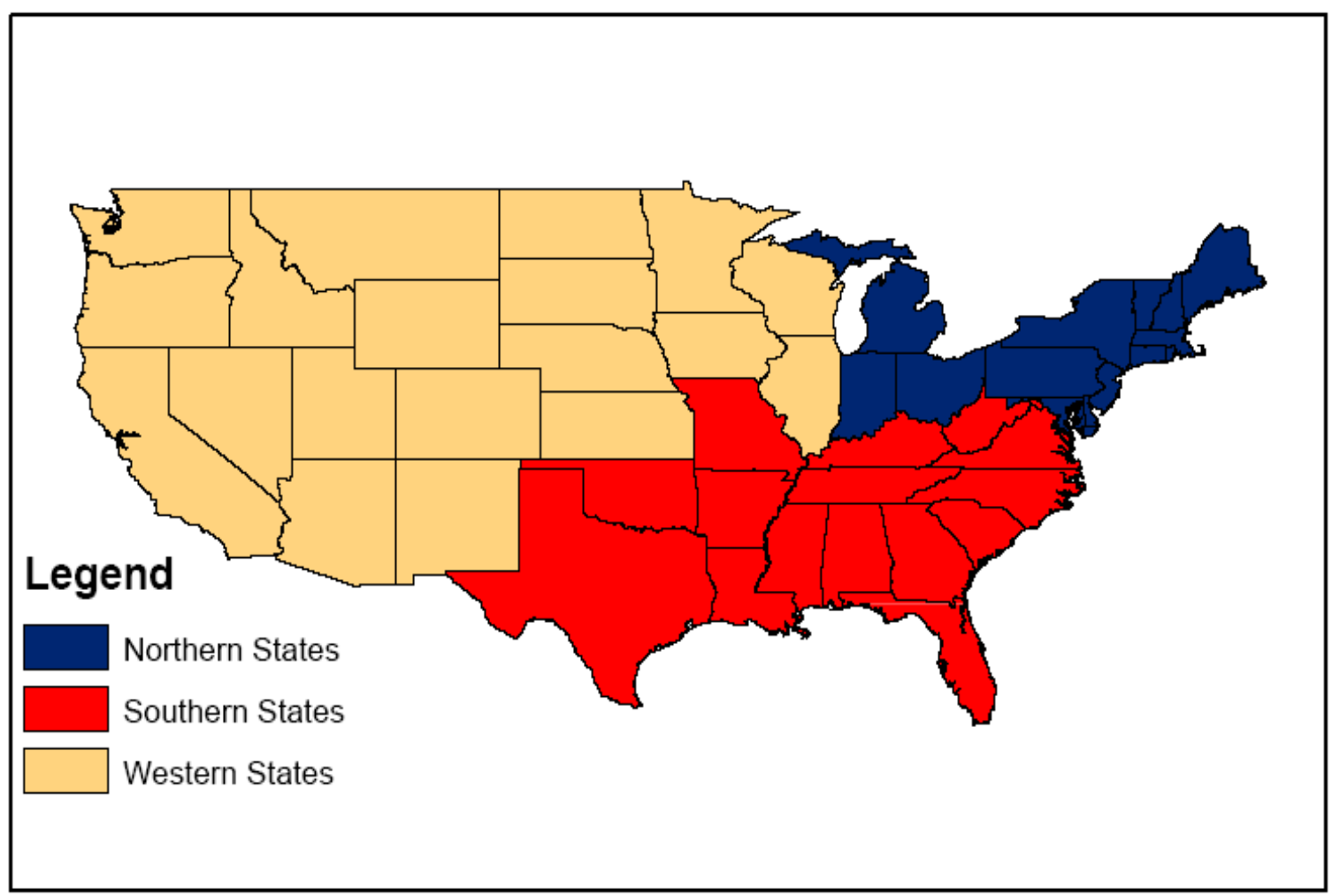

(a) Regional Classification

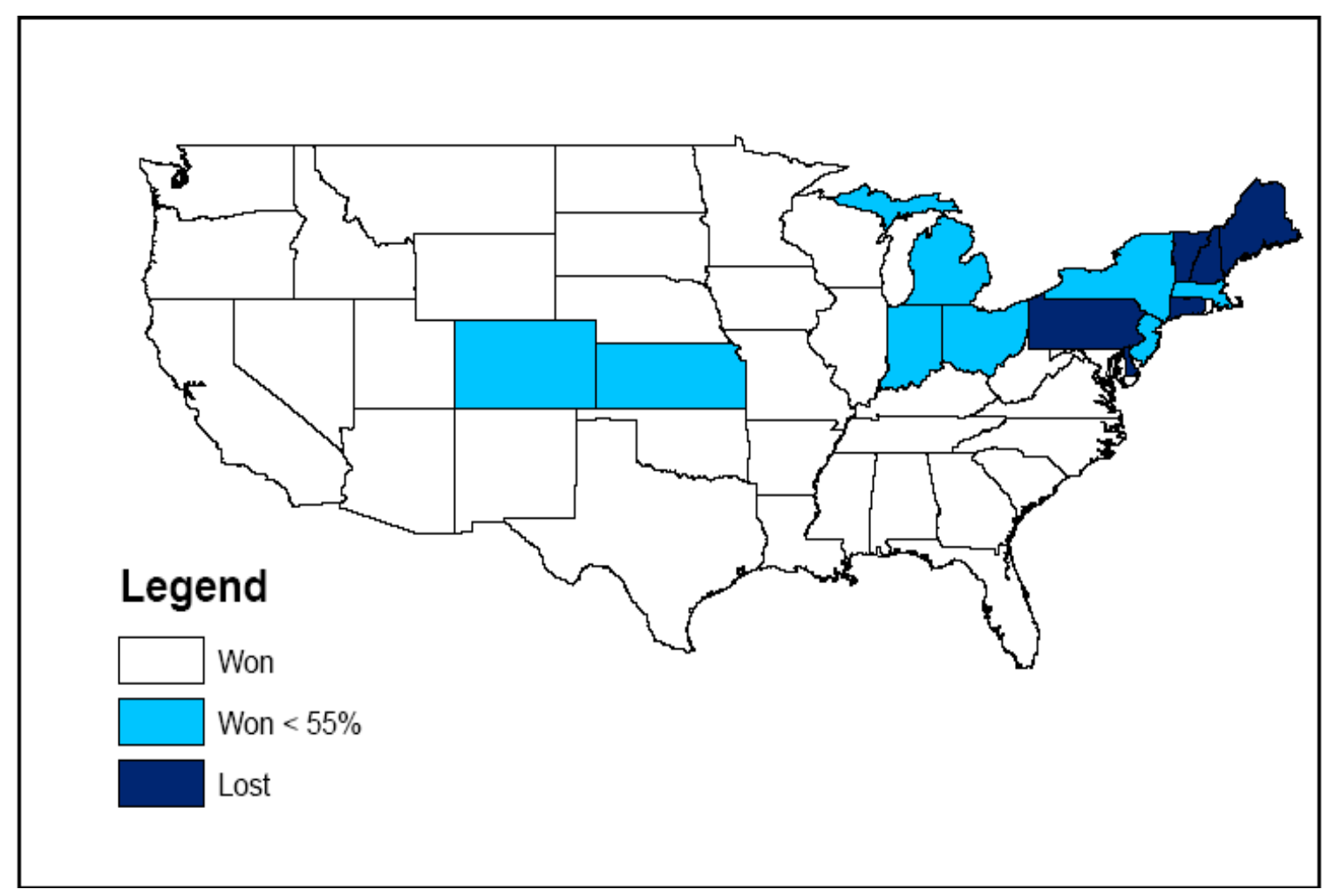

(b) Political Support for FDR

Figure 2: Maps 


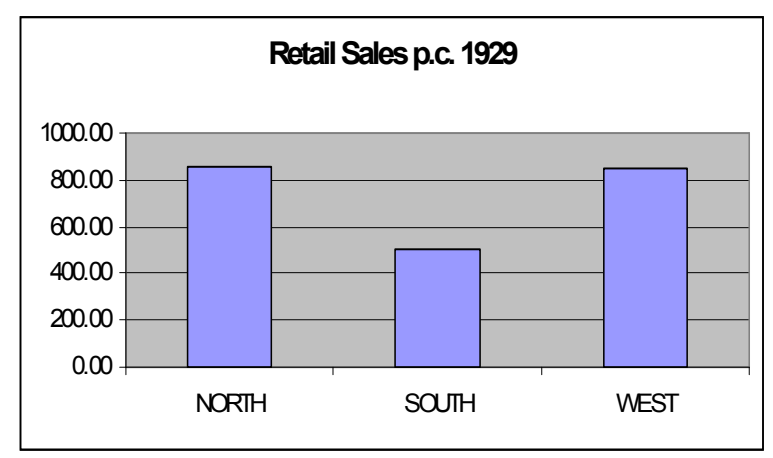

(a)

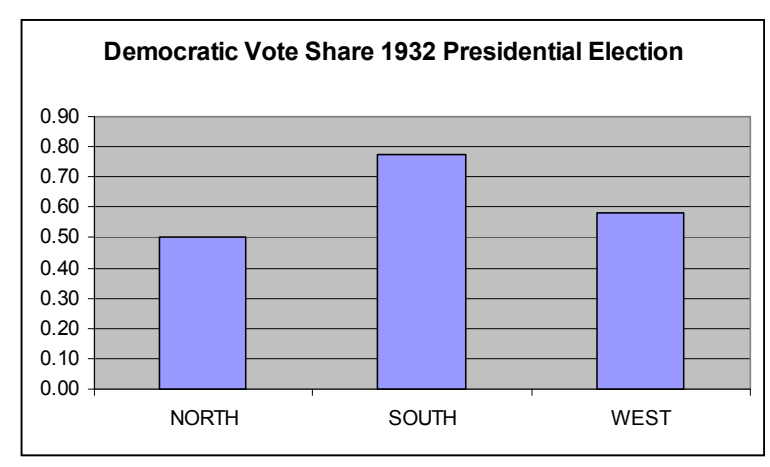

(c)

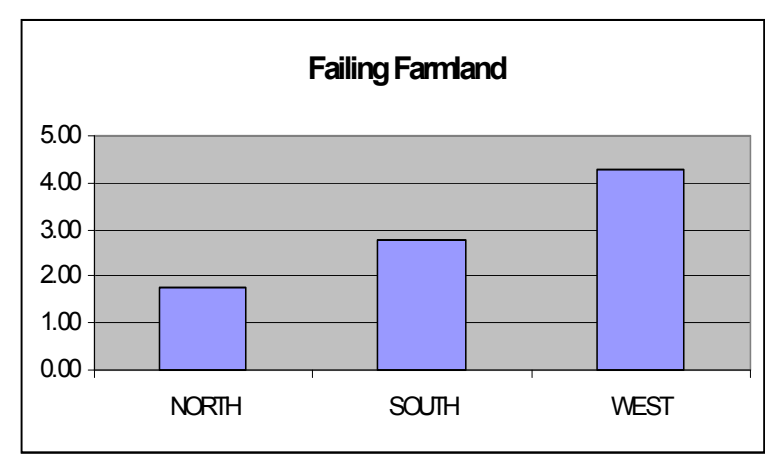

(e)

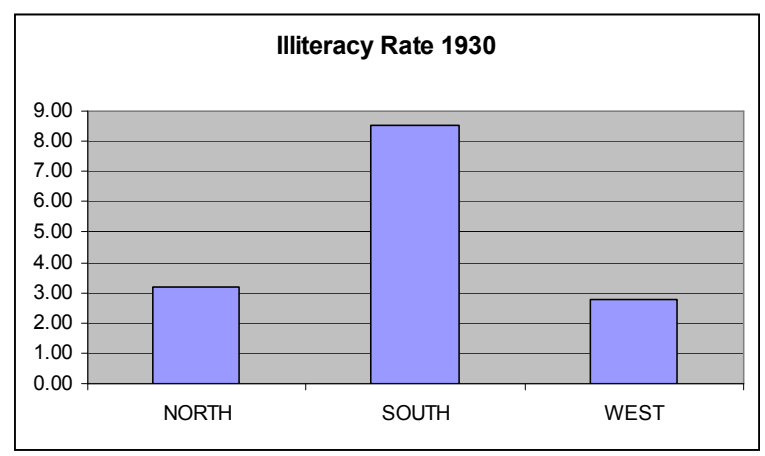

(b)

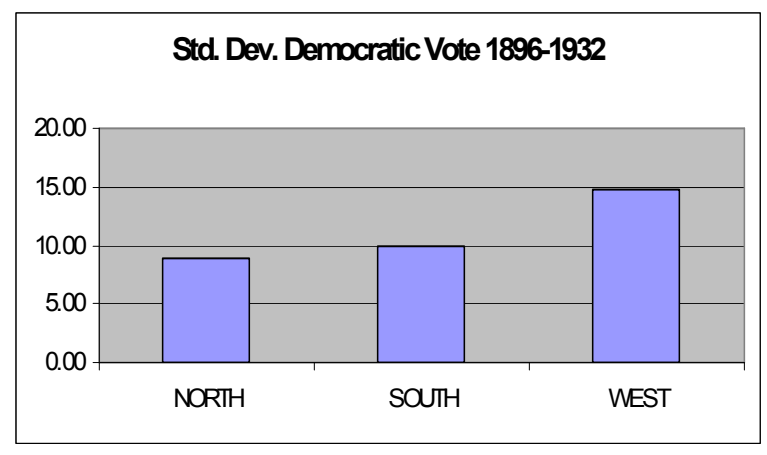

(d)

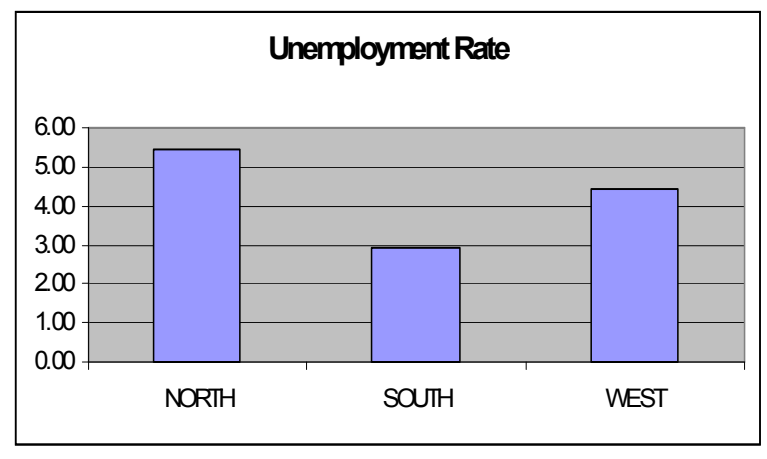

(f)

Figure 3: Regional Characteristics 


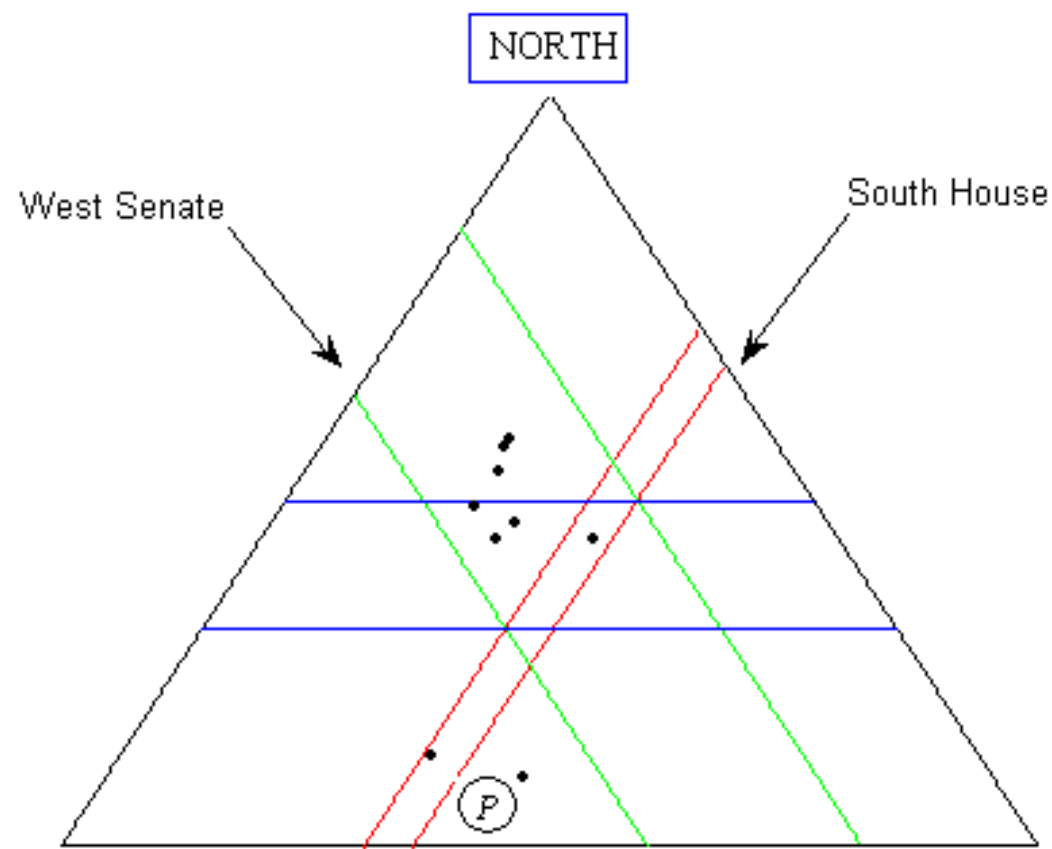

Figure 4: Observed Allocations 